\title{
The Impact of Saudi Arabia King Abdullah's Scholarship Program in the U.S.
}

\author{
Charles Taylor, Wasmiah Albasri \\ School of Education Doctoral Program, Edgewood College, Madison, WI, USA \\ Email: ctaylor@edgewood.edu, WAlbasri@edgewood.edu
}

Received 16 September 2014; revised 20 September 2014; accepted 24 September 2014

Copyright (C) 2014 by authors and Scientific Research Publishing Inc.

This work is licensed under the Creative Commons Attribution International License (CC BY). http://creativecommons.org/licenses/by/4.0/

c) (i) Open Access

\section{Abstract}

This paper provides an overview of the current Saudi educational landscape in the U.S. Information is provided on the King Abdullah Scholarship Program that makes it possible for Saudi students to study abroad, information on the top states and colleges with the largest Saudi student enrollments, and what the future looks like for the Scholarship Program. This paper is the first of two papers dealing with Saudi education in the U.S. The next paper is based on original research and provides the results of surveys administered to Saudi students throughout the U.S. about their experiences on U.S. campuses. Directors of International Programs were also surveyed and the paper contrasts their perceptions with Saudi student perceptions in addressing student needs. The next paper also discusses the impact western education is having on Saudi culture and how Saudi culture is affecting colleges and universities in the U.S.

\section{Keywords}

Saudi International Students, King Abdullah Scholarship Program, Saudi Student Enrollment, Saudi Scholarship in U.S., Saudi U.S. Students

\section{Introduction}

The number of Saudi Arabian students studying in the United States has increased dramatically during the past decade. This explosive growth can be attributed to an educational agreement brokered between former U.S. president George Bush and Saudi King Abdullah bin Abdulaziz Al Saud in 2005 [1]. The agreement opened the doors for Saudi students to pursue their higher educational degrees in the U.S. with their government paying all of their educational expenses. As a result over 100,000 Saudi students were enrolled in American colleges and universities in 2013-14 [2], making Saudi Arabia the fourth largest sponsor of international students to the U.S. [3]. 


\section{History}

The Saudi government has been sponsoring students to study abroad since the reign of King Abdul-Aziz, 18761953, after he laid the foundation of the modern Kingdom of Saudi Arabia in 1932 [4], allowing students to study Arab and Islamic studies in Arab countries such as Egypt and Lebanon, subsequent Kings expanded international study opportunities to include studies in the United States and Europe in 1960. The opportunity to study abroad gained wide popularity and by 1975 thousands of students were being sponsored by the Saudi Arabian government to study abroad in order to obtain degrees in higher education [1].

Prior to 2005 there were less than 5000 Saudis studying in the U.S. The majority of students studying abroad studied outside the U.S. When 9/11/01 occurred the number of Saudi students attending colleges in the U.S. fell to an all-time low. This was due to a security crackdown on Arab travelers since 15 of the 19 hijackers were Saudi Arabians. The tough restrictions didn't ease until 2005 when former president George Bush and King Abdullah inked an agreement to boost educational and cultural programs between the two countries.

For his part King Abdullah created a new scholarship program enabling Saudi students to study in the States and as a result there has been an tremendous increase in Saudi enrollment in U.S. colleges ever since. His scholarship program replaced all prior Saudi international scholarship programs to the U.S. and laid the foundation for the massive growth in Saudi student enrollment depicted in Figure 1.

As Figure 1 shows there has been a steady rise in Saudi enrollment since the introduction of King Abdullah's scholarship program. The scholarship program also influenced where Saudi students studied in the U.S. Prior to 2005 most Saudi students graduated from colleges in the Washington, D.C. area where the Saudi Arabia Cultural Mission was located. SACM was created by the Saudi Arabian government in 1951 to act as a specialized agency for the purpose of ensuring that the cultural and educational needs of the Saudi Arabian students studying in the United States were met. It also acts as a mediator between the educational facility in the United States and the Saudi Arabian government, handling issues concerning science, education, and culture [1].

D.C. is also home to the Royal Embassy of Saudi Arabia and many students felt more secure knowing that their government officials were nearby in case they got into any difficulty while studying in the U.S. An equally compelling reason why many students chose D.C. as their college home was because of the K-12 Islamic Saudi Academy that is located there. The Academy allows Saudi students with children to enroll them in a school that has a similar curriculum and educational structure like the schools in their home country. Since the Saudi government covers most of the students' family expenses, this educational perk made the D.C. area a very attractive educational destiny.

As shown in Figure 2, prior to 2005 schools in Washington, D.C. lead all states in producing Saudi graduates.

\section{About the King Abdullah Scholarship Program (KASP)}

In 2005 the King Abdullah Sponsorship Program (KASP) was established via an agreement between King Abdullah and President George Bush which allowed an increase in the number of Saudi Arabian students in universities in the United States. Although the program is relatively new, having only been in existence for less than ten years, it quickly has become the largest scholarship program in Saudi Arabia's history [1].

Saudi Arabian students have obtained bachelors, masters, and doctorate degrees as well as medical fellowships as a result of this scholarship program. The fields of study that students are allowed to enroll in are chosen by the Saudi Arabian Government based on perceived need of the government and economy. These fields are currently limited to medicine, medical science and health sciences for undergraduate students. Students choose from a limited selection of available majors. Graduate students have more flexibility and opportunities than undergraduate students [5].

While the Saudi Arabian government decides what majors that the students can choose from, the government does not choose the major for each student. A list is compiled of all of the available majors that the students can choose from, and students make their selection from the available options. These majors are carefully selected by the Saudi Arabian government so that no one particular industry is oversaturated when the students return to Saudi Arabia and enter their fields.

The mission of the scholarship program is "To prepare and qualify Saudi human resources in an effective manner so that they will be able to compete on an international level in the labor market and the different areas of scientific research, and thereby become an important source of supply of highly qualified individuals for Saudi universities as well as the government and private sectors" [5].

The program must be renewed every five years and requires the approval of the King based on the needs of the country. 


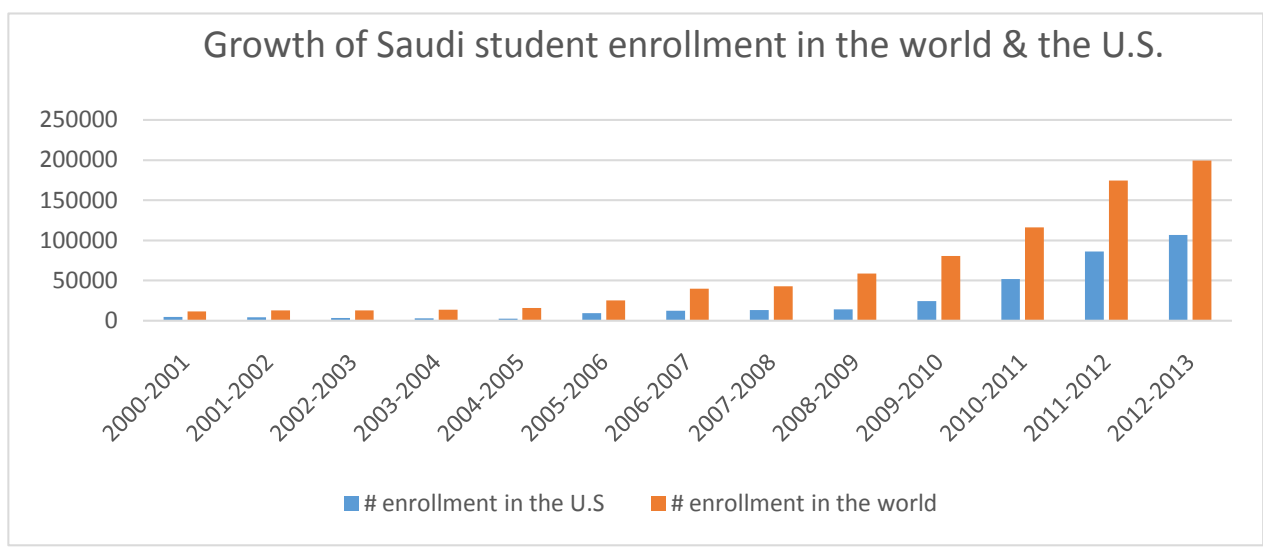

Figure 1. Number of Saudi students enrolled in the U.S. and worldwide. 2012-13 projections were based on 2012 fall enrollments [5].

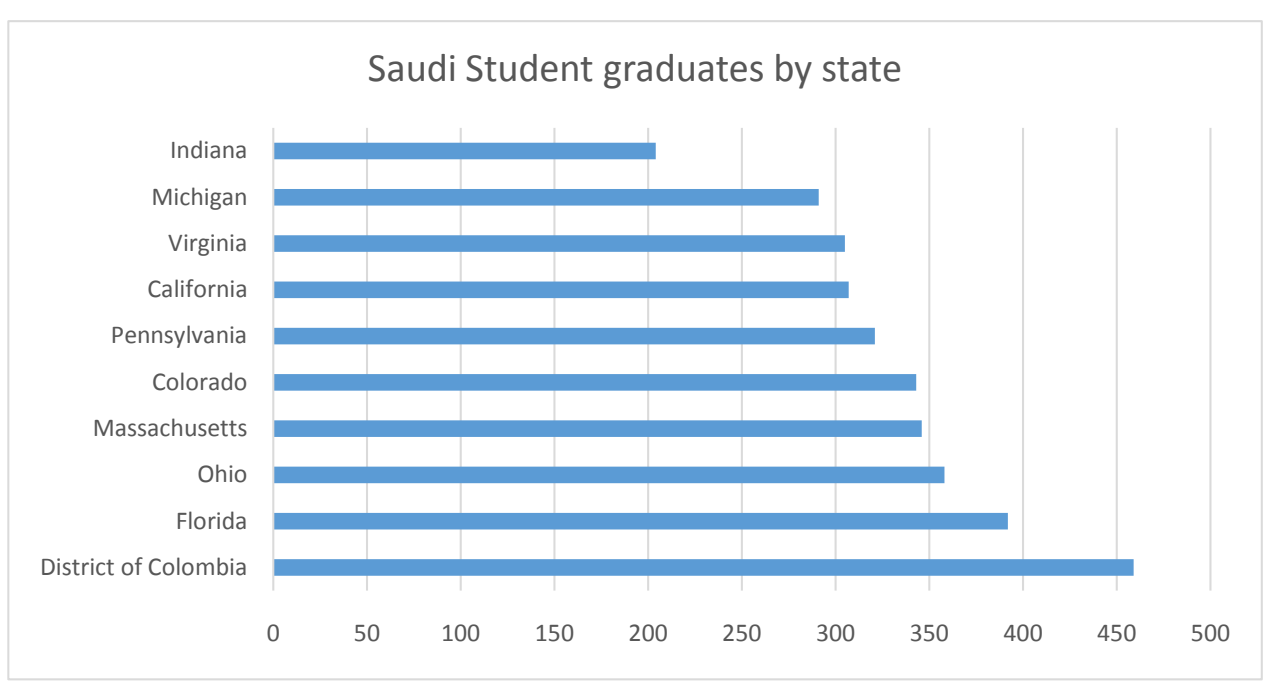

Figure 2. States with most Saudi Arabian student graduates from 1995-2005 [1].

\section{Goals of KASP}

The central focus of KASP is to give students the knowledge and skills that they need to become successful, not only for themselves but for the benefit of the country. These students are being molded to be future leaders in their country. In addition to this, KASP is also designed with the goals of increasing patriotic communication, to extend a mutual understanding of cultures with the countries that the students study in, and to allow a cultural exchange with the intention of being mutually beneficial for both Saudi Arabia and the host country [1].

There are a great number of benefits for the students who participate in the scholarship program. These benefits extend to their families as well. Few countries currently match the generosity of the KASP program.

Students enjoy the following benefits:

- Monthly stipend, which is awarded to the students, their spouses, and their children

- A full scholarship which covers all academic expenses

- Medical and dental coverage

- Complimentary round trip tickets for the students and their families to return to Saudi Arabia once a year

- Academic supervision

- Rewards for obtaining a high GPA

- Allowances for scientific materials

- Allowances for private tutor fees

- Allowances for special needs [1] 


\section{Duration of the Scholarship}

Undergraduate students receive four years of funding, while Master's students receive two years of coverage and $\mathrm{PhD}$ students are funded for three years. Extensions may be granted in exceptional cases. Each student is provided with academic advisors to ensure that the student graduates within their prescribed time [6].

\section{Eligibility}

Candidates must be Saudi Arabian citizens in order to be eligible for the scholarship program. Secondly, they must have a high Grade Point Average. They must also be a full time student and agree to reside in the country that their scholarship is issued to. While the scholarship is awarded to both male and female Saudis, a female student must have a male guardian to travel with her. The guardian is required to stay with her through the completion of the scholarship program. Guardian expenses are covered by the program.

In addition to these requirements, there are also specific requirements based on the type of degree being sought. For example, in order to apply for the bachelor degree scholarship, the applicant cannot be older than twenty-two years. For the doctoral degree scholarship, the applicant cannot be older than thirty [5].

\section{Application Process}

The application process for the KASP is extensive because the program is very competitive. It requires applicants to first register online once they are notified that the program is open. Applicants who do not qualify for the program are filtered out, and those who meet requirements are required to bring their application documents to one of the program's six admission centers. There is a nomination process, and those who make it past this stage are announced in the official Saudi newspaper and on the KASP's website. Those rejected have the opportunity to appeal [5].

Those selected to receive scholarships begin to prepare for what they will experience in their host country. They sit through seminars and lectures informing them of possible issues that the country that they are going to might cause them. They study the laws and customs of the country, the rules and duties of the scholarship program, and engage in psychological, social, self-improvement, religious and awareness activities. Following this, travel arrangements are made to send the student to his or her destination [5].

\section{Self-Sponsored and Employer Scholarship Students}

There are two other options for Saudi students interested in studying abroad: self-sponsored and employer sponsored programs. Self-sponsored students are able to study abroad without a scholarship to provide their funding. They must receive a letter of acceptance from their university of choice which completes $80 \%$ of the KASP enrollment requirements to apply. They are not guaranteed acceptance into the program, and their confirmation or denial into the program may take up to two weeks to be completed [6].

An employer sponsored scholarship student is one in which the employer covers the expenses of the student. Typically, these students study abroad to learn a specific skill or study in scientific or high tech fields. Once their study is completed, they are expected to return to their employment in Saudi Arabia.

Dr. M. Al-Ahmed, the General Manager of Observation of Higher Education in Saudi Arabia provided data shown in Figure 3. According to his data $76 \%$ of all Saudis studying abroad do so through KASP. It's important to note that nearly $25 \%$ of students have access to other resources to study abroad. Both individuals and employers are investing in international education [7].

\section{Where Do Saudi Students Study Abroad?}

Dr. M. Al-Khalaf, Assistant Cultural Attaché for cultural and social affairs at SACM, said that today, the majority of Saudi Arabian Students studying abroad are located in the U.S. Students can get one of the world's best educations through the United States' educational system [8].

According to Quacquarelli Symonds World University ranking, out of the top twenty world's best universities, thirteen of these are located in the United States [9].

When an education system appears to be weakening, they tend to seek international opportunities. Ranking at only 93rd out of 129 countries educationally in 2008, many Saudis felt they needed to seek education abroad in 


\section{How Saudi Students Study Abroad}

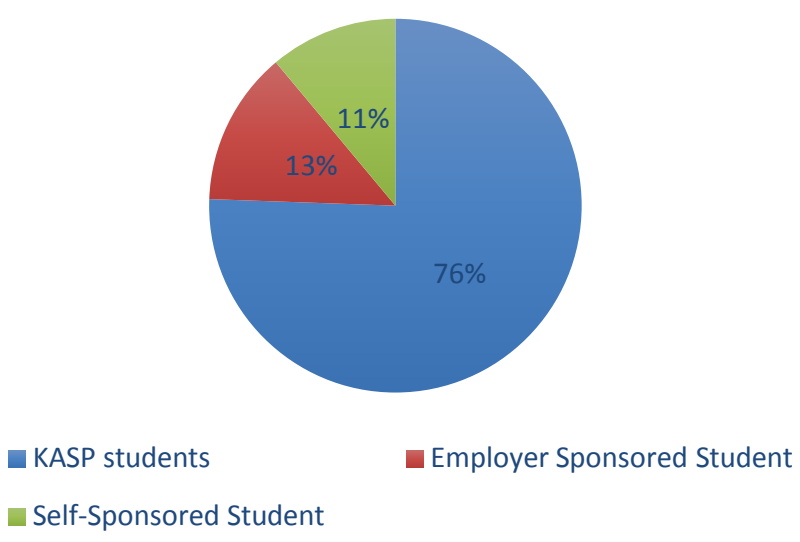

Figure 3. Percentage of students studying abroad by program type [7].

order to remain competitive. As a developed nation, a degree from the United States is viewed as more valuable than that of a developing nation. Therefore, having a degree from the United States is a powerful thing to hold, and although Saudi Arabia is wealthy, the ranking of their educational system makes it clear that it is still in a developmental stage [10].

The strongest influences, however, may be the policies of the King Abdullah Scholarship Program which directs students to the U.S. because of the educational agreement between both countries [10].

Figure 4 shows the impact of KASP when comparing Saudi students studying in the U.S. compared to the percentage of Saudi students studying in other countries.

Currently Saudi students study in Canada, the United Kingdom, Ireland, France, Spain, Italy, Australia, Germany, the Netherlands, Poland, New Zealand, Austria, Hungary, the Czech Republic, Singapore, South Korea, Japan, the People's Republic of China, Malaysia, India and South Africa, according to the Ministry of Higher Education's website. Despite all of the countries mentioned above, the U.S. is now the preferred choice of most Saudi students.

Figure 5 reveals that four countries-the U.S, Great Britain, Canada, and Australia account for most of the growth of Saudi student enrollment worldwide. Saudis are clearly signaling that they value the education they're getting from Western countries. One of the major reasons for this is because of the language spoken in these countries, which means that English is the language Saudis prefer to learn.

\section{Top 7 Countries Sending Students to the U.S.}

Saudi investment in higher education has resulted in it being among the top four countries that permit students to earn degrees abroad. Currently, China is the world leader with nearly $28.7 \%$ of the total number of foreign student in the U.S., India-11.8\%; South Korea-8.6\%; and Saudi Arabia is the fourth leading country with 5.4\% as of 2012-13 [3].

Table 1 shows the top seven countries sending their students to the U.S. according to U.S. Immigration and Customs Enforcement in 2014.

\section{Annual Cost of Scholarship Program}

The Saudi government is projected to invest over $10 \%$ of its annual budget to higher education for the foreseeable future [5]. Currently it invests nearly $\$ 2.4$ billion in the KASP initiative annually, which includes academic funding as well as living expenses for over 100,000 students enrolled in graduate and undergraduate programs in the U.S. [12]

If the Saudi government continues to support KASP at the current level, it will soon surpass South Korea in terms of sending more students abroad to study. 


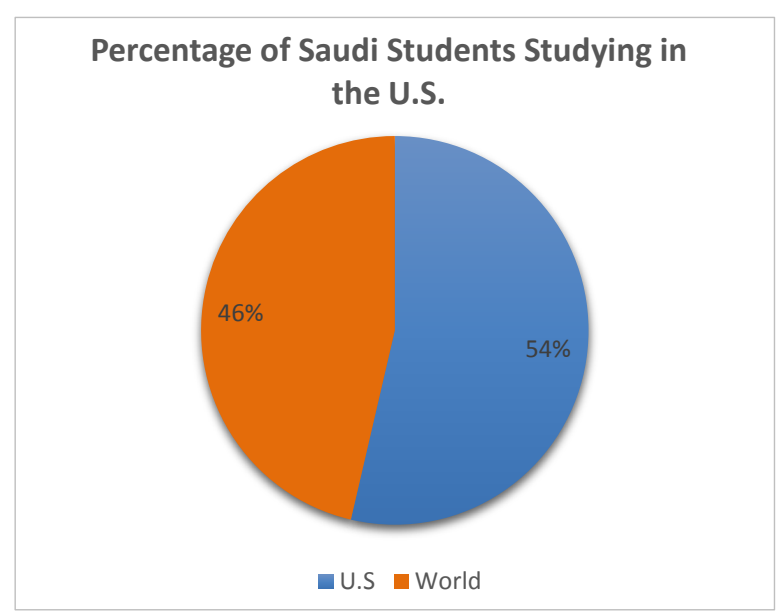

Figure 4. Percentage of Saudi students studying in other countries and the U.S. in 2012-2013. Percentages include self-sponsored students, KASP students and employer sponsored students [5].

TOP COUNTRIES THAT ENROLL MOST SAUDI STUDENTS

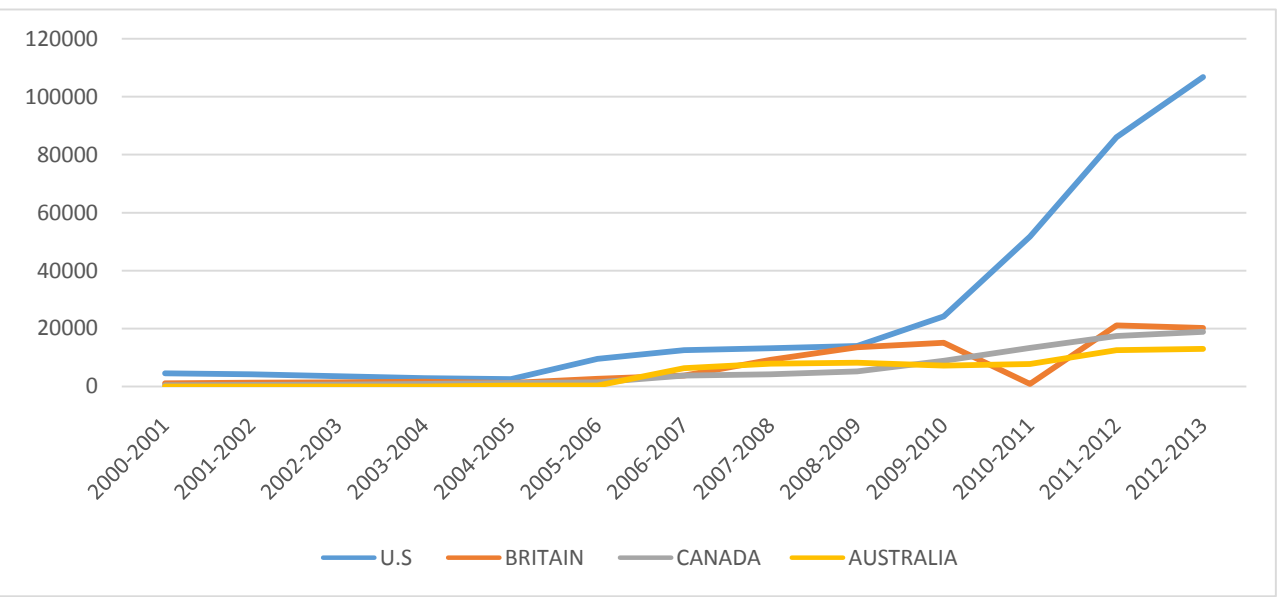

Figure 5. Enrollment growth of Saudi students in four countries [5].

Table 1. Top seven countries sending students to the U.S. [11].

\begin{tabular}{cc}
\hline Rank & Country \\
\hline 1 & China \\
2 & India \\
3 & South Korea \\
4 & Saudi Arabia \\
5 & Japan \\
6 & Taiwan \\
7 & Vietnam \\
\hline
\end{tabular}

\section{What States in the U.S. Enroll the Largest Number of Saudi Students Since KASP Started?}

Prior to the KASP program, the district of Colombia led all states in Saudi student enrollment. The KASP program essentially opened up the country to Saudi students. As a result, since 2005, Figure 6 shows California 
now leads all states with over 11,000 students attending college there. California has over 80 public and private colleges that are approved by Saudi's Ministry of Higher education for participation in the KASP project, more than the other Top 10 states, except for Pennsylvania which has around 90 colleges that are approved. California also attracts students because of its weather and its many attractions that appeal to international travelers.

Although the state of California enrolls more Saudi Students than any other state, Figure 7 shows that no school in California made the top 10 list in the U.S. colleges with the largest Saudi student enrollment. That distinction goes to Cleveland State University in Ohio which enrolled nearly 700 Saudi students during the 20132014 academic year [8].

California as a state enrolls the most Saudi students but because of its large number of colleges and universities, students are widely dispersed and as a result California's colleges failed to make the top list of colleges with the largest Saudi student enrollments. In addition, the Midwest has a large population of Arabic people offering students a community similar to what they might experience back home.

\section{How Does a College Get on the Ministry's List?}

Not every college or university in the U.S. is eligible to participate in the Scholarship Program. Saudi's Ministry of Higher Education must approve all foreign colleges before students are permitted to apply for admission. Dr. M. Al-Abaishi, the director of academic accreditation at SACM, stated that the colleges and Universities are added to the Ministry of Higher Education's list only after recommendations from specialized committees, one of which is the Academic Accreditation Committee [13].

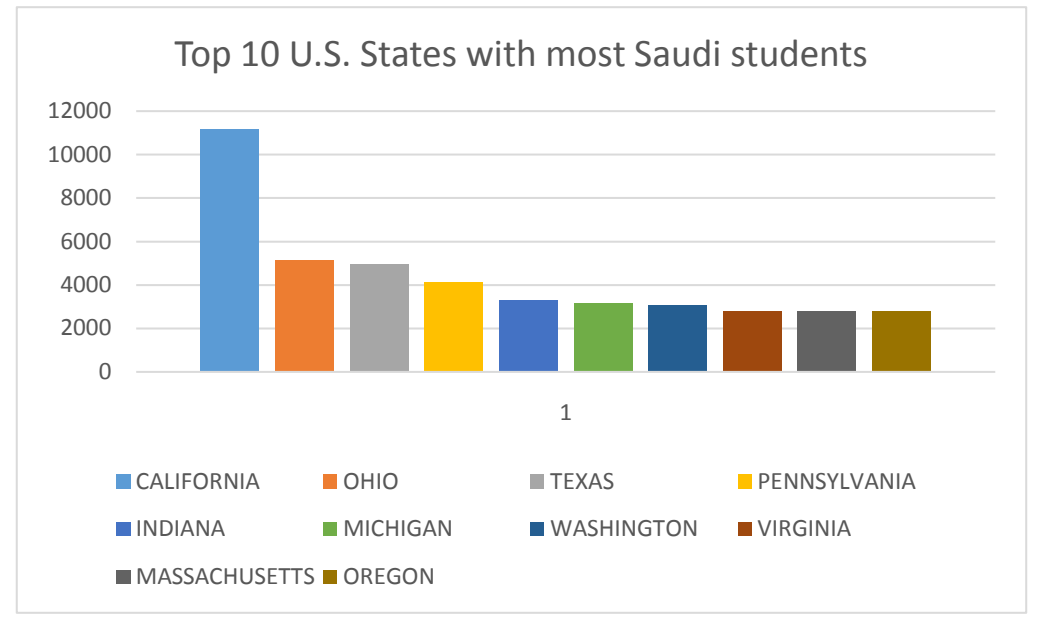

Figure 6. States in the U.S. that enroll the largest number of Saudi students [8].

Top 10 U.S. colleges with the largest Saudi student enrollment.

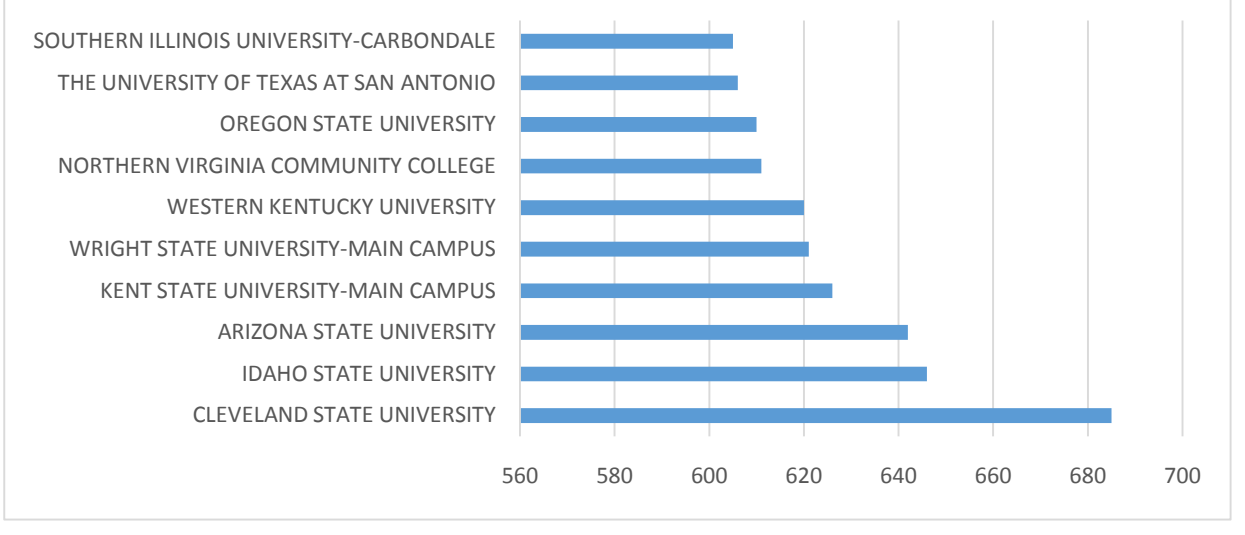

Figure 7. U.S. colleges with the largest Saudi student enrollment [8]. 
Until recently, Saudi Arabian students were restricted from attending community colleges; however, in the fall of 2012, the government accepted community colleges as "Approved Institutions of Learning" for the first time in Saudi Arabian scholarship history [14]. Officials felt that both students and the country could benefit by having access to the many specialized fields that community colleges offer.

\section{Job Opportunities for KASP Graduates}

Opportunities for graduates start almost immediately once they earn their degrees. A job fair is held annually in Saudi Arabia that hosts over 130 recruiters looking to fill jobs. Graduates are flown in from all over the world to meet with these recruiters. Although no guarantees for a job are made, students are given every opportunity to obtain a job through these efforts [8].

The jobs picture has not been very rosy in recent years. Saudi Arabia has not been exempt from the economic crisis that has plagued most of the world's nations during this decade. Unemployment stands at $12 \%$ with nearly half of the unemployed holding a bachelor's degree [15]. The high unemployment rate could potentially harm the Scholarship Program and reduce public support for it [10].

Dr. L. Al-Dakheil, former Vice Dean of Scientific Research in Princess Nora University, stated that the current Saudi job market is not as it used to be in the past. Unlike before, Saudi graduates from developed Western countries, like the U.S. and the U.K., can't easily land jobs once they return to Saudi Arabia. With the recent development in the Saudi job market and the greater demand for higher job qualifications, graduates now are facing multiple employment tests and job interviews to assess their qualifications for the position. While graduates from the West used to land jobs easily based on the countries they graduated from, this is no longer the case. Some of these western-educated graduates failed to pass these employment tests, while their nationallyeducated counterparts passed them [16].

\section{How Does the U.S. Benefit from the Scholarship Program?}

The United States benefits culturally, educationally and economically. The several billion dollars that Saudi students and their families spend annually benefits many sectors of the economy in areas such as housing, food, recreation, and transportation to name a few. Saudi students are also covered extensively through their health insurance plans, which directly benefit the American health care industry.

According to the Department of Commerce, international students contributed $\$ 22.7$ billion to the American economy in 2011 [2]. Saudi students contributed \$3.2 billion during the 2013-2014 academic year alone [17].

Besides the dollars that obviously make a real contribution, Saudi students bring cultural gifts to the table as well. When a student body has a good amount of diversity, it creates an environment that is culturally, economically, and educationally beneficial to universities and colleges in the United States. By increasing the numbers of international students the level of cultural sensitivities and global understanding of Americans also increases, which may give them the necessary skills to be able to interact with people of different backgrounds in the workplace [10].

\section{What Does the Future Look Like for the Scholarship Program?}

The U.S. will probably continue to receive the largest share of Saudi students [8]. Because Saudi students tend to stick together while studying in the United States rather than integrating with Americans, sending Saudi students from different family groups to the United States has promoted a greater understanding between different groups of Saudis. This could result in unifying disparate Saudi political groups in the future once they get back home [10].

The academic difficulties experienced by some Saudi students may have less to do with language and the rigorous educational system of the United States and more to do with Saudi students being ill-prepared for higher education in general, as Saudi school systems are not up to par with American educational systems and how they function as a class [10].

There have been over 500 Saudi KASP students recalled and expelled from the international scholarship program by the Saudi Ministry of Higher Education as a result of weak performances and poor attendance at the universities they were attending. This recall draws attention to the difficulty that some Saudi students are having studying at foreign institutions. Consequently, the ministry now requires students to attend an extensive orienta- 
tion before they leave for the foreign country that they are going to be studying at [18]. The hope is that a rigorous orientation will prevent some of the academic and cultural adjustment problems that students face.

Perhaps a red flag worth watching is the number of Saudi students coming to the United States to study in combination with the lack of supervision of these students. This has the potential to become a problem over the next decade. Despite such challenges, Dr. Al-Khalaf states that the scholarship program has become so popular in Saudi Arabia that nearly every family in Saudi Arabia has one or more scholarship student in the program [14].

The good news is that there is still strong support for the program by the government. The SACM is looking ahead and expecting the funding to be continued. They have already inducted the newest group of students who are not scheduled to graduate until 2020 [8]. Saudi Arabia will continue to benefit from this program culturally and educationally.

KASP is clearly impacting Saudi Arabia. The Alumni are bringing their experiences from the United States back to Saudi Arabia and are trying to recreate them [8]. The impact that the exposure of the American culture has on these students will have an impact on the future of Saudi Arabia, even if the impact is not immediately felt [10]. The program seems to be very successful both academically and culturally [8].

The large investment in education bodes well for Saudi Arabia's future. With a population approaching 21 million people, nearly $20 \%$ of its population holds at least a bachelor's degree [15]. Although there are no official goals to increase that figure by 2020 , as long as the scholarship program exists, the numbers should increase.

The King Abdullah Scholarship Program has made a lasting impact on the future of Saudi Arabian education. Alumni from the program have studied in the world's top universities and they're bringing this knowledge home to help transform their educational system.

KASP has similarly impacted the culture of Saudi Arabia. These students absorbed and learned from the culture of the country that they studied in. They raised children in the country, albeit temporarily, they become a part of that culture, thereby bringing some of that culture back to Saudi Arabia, expanding the potential for Saudi Arabia to show significant cultural changes in the future; and become more open and accepting of other societies.

The future of KASP looks strong, although it may someday be limited to majors that are not offered in Saudi Arabia. KASP students will continue to bring new ideas that lead Saudi Arabia to a more open culture that will make it more competitive in global markets. KASP graduates are poised to become influential as world leaders as a result of the knowledge and experience that they gained from studying abroad. Education is perhaps one of the best investments a government can make in its people and KASP is one of those rare programs that other countries would do well to emulate it.

\section{References}

[1] (2012) Saudi Arabia Cultural Mission to the U.S. http://www.sacm.org/ArabicSACM/pdf/Posters_Sacm_schlorship.pdf (n.d) http://www.sacm.org/AboutSACM/History.aspx (2006) http://www.sacm.org/ArabicSACM/pdf/56448_saudi_grads_lresARABIC.pdf

[2] Naffee, I. (2014). Number of Saudi Students in US Reaches 111,000. Arab News. http://www.arabnews.com/news/558416

[3] DeSilver, D. (2013) Record Number of International Students Studying in U.S. (News in the Numbers). Pew Research Center. http://www.pewresearch.org/fact-tank/2013/11/12/record-number-of-international-students-studying-in-u-s/

[4] Ministry of Foreign Affairs (2013) About Saudi Arabia. http://www.mofa.gov.sa/sites/mofaen/ServicesAndInformation/aboutKingDom/Pages/KingdomGeography46466.aspx

[5] (2012) Saudi Arabia Cultural Mission to the U.S. http://www.sacm.org/ArabicSACM/pdf/Posters_Sacm_schlorship.pdf (2011) http://www.mohe.gov.sa/en/studyaboard/King-Abdulla-hstages/Pages/study-levels-academic-disciplines-a.aspx http://www.mohe.gov.sa/en/studyaboard/King-Abdulla-hstages/Pages/mission-a.aspx https://safeer.mohe.gov.sa/sites/student/SInterested/ScholarshipTerms/SCHOLARSHIPRULES/Pages/Rules2.aspx (n.d) http://www.mohe.gov.sa/ar/Ministry/SCHOLARSHIPSAGENCY/Pages/kas.aspx

(n.d) http://www.mohe.gov.sa/ar/faqs/Pages/default.aspx

(2014) http://www.mohe.gov.sa/ar/news/Pages/25_1_2014.aspx 
[6] Saudi Arabia Cultural Bureau in Canada (2014) King Abdullah Scholarship Program: Selection, Policies and Requirement.

http://grad.ucalgary.ca/sites/grad.ucalgary.ca/files/kasp-sacb-guidelines-kasp-student-selection-policies-and-requireme nts.pdf

[7] (2014) Al-Ahmed, Personal Communication, 3 August 2014.

[8] (2014) Al-Khalaf, Personal Communication, 3 June 2014.

[9] Tempera, J. (2013) Foreign Students Examine Benefits of Studying in U.S: Great Colleges, Diversity and Great Job Opportunities Are Just a Few of the Reasons Foreign Students Choose to Study in America. USA Today. http://www.usatoday.com/story/news/nation/2013/06/12/foreign-students-studying-usa/2416313/

[10] Hall, T.R. (2013) Saudi Male Perceptions of Study in the United States: An Analysis of King Abdullah Scholarship Program Participants. Doctoral Dissertation, Western Kentucky University. http://digitalcommons.wku.edu/diss/50

[11] US Immigration and Customs Enforcement (2014) Student and Exchange Visitor Information System. http://www.ice.gov/doclib/sevis/pdf/by-the-numbers1.pdf

[12] International Consultants for Education and Fairs (ICEF) Monitor (2012) Enormous Saudi Scholarship Programme Extended to 2020. http://monitor.icef.com/2012/02/enormous-saudi-scholarship-programme-in-the-spotlight/

[13] (2014) Al-Abaishi, Personal Communication, 7 August 2014.

[14] McMurtrie, B. (2012) China Continues to Drive Foreign-Student Growth in the United States. The Chronicle of Higher Education. http://chronicle.com/article/China-Continues-to-Drive/135700/

[15] Central Department of Statistic \& Information. Population (15 Years and over) by Age Groups and Educational Status: 1434H/2013D \& Unemployment Rates (15 Years and above) by Sex. http://www.cdsi.gov.sa/english/index.php

[16] (2014) Al-Dakheil, Personal Communication, 7 August 2014.

[17] Saudi Gazette (2014) Saudi Students in U.S. Universities Contribute \$3.2b to US Economy. http://www.saudigazette.com.sa/index.cfm?method=home.regcon\&contentid=20140604207390

[18] Mills, A. (2008) Poorly Performing Students Ordered Home by Saudis. The Chronicle of Higher Education. http://chronicle.com/article/Poorly-Performing-Students/36571 
Scientific Research Publishing (SCIRP) is one of the largest Open Access journal publishers. It is currently publishing more than 200 open access, online, peer-reviewed journals covering a wide range of academic disciplines. SCIRP serves the worldwide academic communities and contributes to the progress and application of science with its publication.

Other selected journals from SCIRP are listed as below. Submit your manuscript to us via either submit@scirp.org or Online Submission Portal.
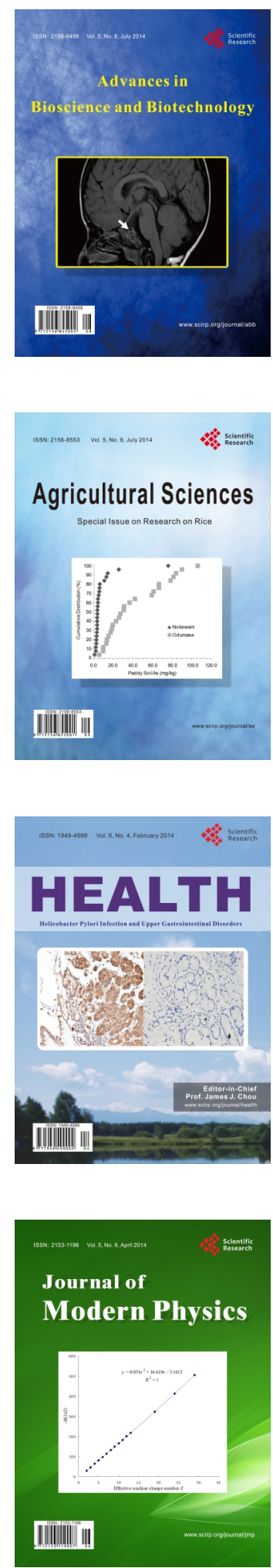
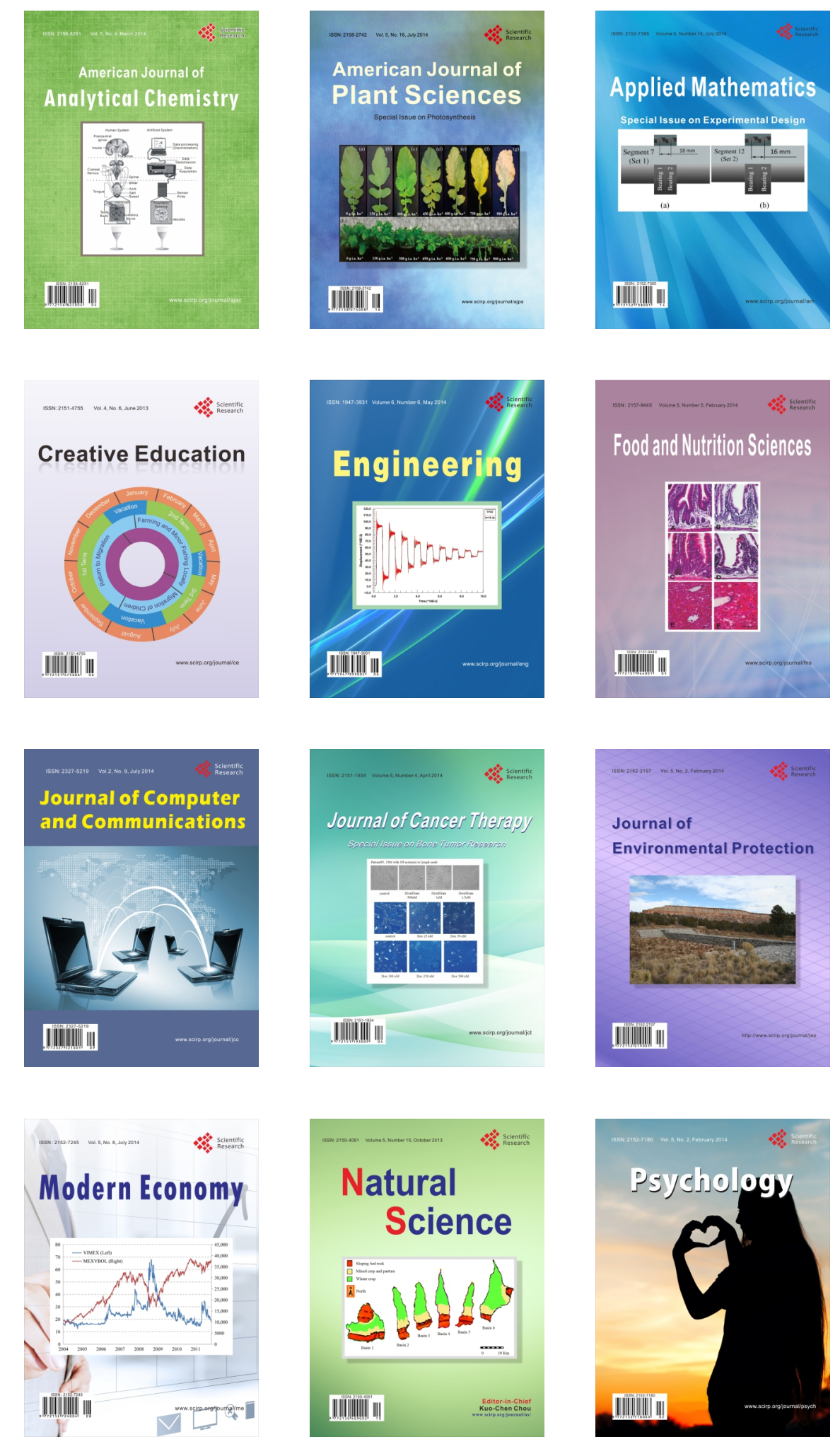